\title{
Naturalism and political science adaptation to the non-classical world picture
}

\section{T. A. Alekseeva ${ }^{1}$}

${ }_{1}^{1}$ MGIMO-University of the Russian foreign Ministry, 76 Vernadsky Avenue, Moscow 117454, Russian Federation

DOI: $10.18255 / 2412-6519-2020-2-112-121$

Research Article

Full text in Russian

One of the greatest achievements of the humanity is obviously the recognition of the systematic unity of the natural and social knowledge. However, this recognition was not constant. The forming development and history of political sciences reflected it rather evidently, tending to go from one extreme to another - from identifying its methods with natural, to pretending for its uniqueness, or even universality. All these questions got a special importance in the perspective of the new non-classical world picture, but the adaptation of political sciences to a new type of thinking meets considerable difficulties.

The analysis of the most significant approaches towards the political and international processes demonstrate, that the acceptance of the new postulates od none-classical and postnone-classical pictures of the world is quite complicated. Simultaneously with the preservation of the pure mechanistic, approach some of the elements of the new world pictures were taken from quantum physics, biology, as well as the chance factor and the rejection of the casual relationships. Nevertheless, it is better to speak not about the translation of the methods and approaches from natural sciences to political, but about the attempts to build "weak" theories or analogues (for instance, quantum-like theories). Nevertheless, generally speaking, political as well as other social sciences tend to be developing accepting the zeitgeist.

The adaption of political sciences to the new world pictures is inevitable,, but would be limited by definition. Even with the backgrounds of the unity of knowledge as such, its methods and instruments are quite different and even during the process of adaption change so significantly and are so greatly reduced, that they preserve only names and imitation of the other sciences' methodology. Anyway, we should follow the parallelcourse.

Keywords: Scientific world picture, "classical” world picture, non-classical world picture, post nonclassical world picture, quantum physics, political science

INFORMATION ABOUT THE AUTHORS

\begin{tabular}{l|l} 
Alekseeva Tatiana A. & $\begin{array}{l}\text { E-mail: www.polittheory@mail.ru } \\
\text { Doctor of Sciences in Philosophy, Professor, Honored Scholar of the Russian } \\
\text { Federation, Chair of Political theory }\end{array}$
\end{tabular}

For citation: Alekseeva T. A. Naturalism and political science adaptation to the non-classical world picture // Social'nye i gumanitarnye znanija. 2020. Vol. 6, No 2. P. 112-121. (in Russ.)

(C) Alekseeva T. A., 2020

This is an open access article under the CC BY-NC-ND license (http://creativecommons.org/licenses/by-nc-nd/4.0/) 


\section{Политическая наука \\ в поисках нового мышления}

\section{Т. А. Алексеева ${ }^{1}$}

${ }_{1}^{1}$ МГИМО - университет МИД России, проспект Вернадского, 76, Москва, 117454, Российская Федерация

DOI: 10.18255/2412-6519-2020-2-112-121

удК 30.328

Научная статья

Полный текст на русском языке

Одним из важнейших достижений человечества стало признание системного единства естественно-научного и социального познания. Признание этого, однако, имело место отнюдь не всегда. Это весьма наглядно проявилось в истории становления и развития политических наук, которые на разных этапах бросались из крайности в крайность, то отождествляя свои методы с естественно-научными, то претендуя на собственную уникальность, а то и универсальность. С точки зрения методологии эти вопросы приобрели особенно важное значение на фоне новой неклассической картины мира, однако адаптация политических наук к новому типу мышления сталкивается с изрядными трудностями.

Наряду с сохранением влияния чисто механистического подхода имели место попытки обращения к отдельным элементам новых картин мира, в частности к квантовой физике, биологии, использования фактора случайности, отказа от причинноследственных моделей. Однако в большинстве случаев можно говорить не столько о трансляции методов и подходов из естественных наук в политические, сколько о попытках выстраивания «слабых» вариантов теорий или некоего подобия (например, квантовоподобных теорий), хотя в целом политические науки, равно как и другие социальные науки, все же стремятся развиваться в духе времени.

Адаптация политических наук к новым научным картинам мира неизбежна, но по определению ограничена: при всем единстве знания как такового их методы и инструменты весьма различны и даже в процессе приспособления претерпевают столь значительные изменения и упрощения, что зачастую сохраняют лишь наименования и имитацию методологии других наук. И все же как минимум придется идти параллельным курсом

Ключевые слова: научная картина мира, «классическая» картина мира, «неклассическая картина мира», «постнеклассическая» картина мира, квантовая физика, политическая наука

ИНФОРМАЦИЯ ОБ АВТОРАХ

Алексеева Татьяна Александровна

E-mail: www.polittheory@mail.ru

Доктор философских наук, профессор ,заслуженный деятель науки РФ, заведующий кафедрой политической теории

Для цитирования: Алексеева Т. А. Политическая наука в поисках нового мышления // Социальные и гуманитарные знания. 2020. Том 6, № 2. С. 112-121. 
Одной из остро дискуссионных тем в политологическом сообществе в последнее время стал вопрос о «кризисе», «упадке», догматизированности и даже крайней идеологизированности политической науки. В самом деле, в последние десятилетия, на первый взгляд, не видно каких-то знаковых «прорывов», появления новых «больших» теорий, способных радикально изменить политологический ландшафт. Вспоминая Томаса Куна, мы как бы застряли в стадии «нормальной науки», накапливая аномалии (называя их «проблемами») и делая относительно робкие шаги в сторону других наук, сплошь и рядом ограничиваясь зачастую необоснованной методологической эклектикой. Так ли это? Или «научная революция» все же произошла или даже происходит на наших глазах, а мы просто в силу инерции, лени или ограниченности предпочитаем ее не замечать? Организаторы сегодняшнего семинара заговорили даже о поисках нового политического мышления, предполагая, по-видимому, что традиционное, привычное на наших глазах устаревает и перестает адекватно отражать и анализировать быстро изменяющуюся реальность.

Забегая вперед, хотелось бы сразу сказать, что мой ответ на вопрос о «кризисности» политической науки амбивалентен: и «да», и «нет». Попробуем разобраться, что же все-таки происходит. Начнем с того, в чем же все-таки проявляется «кризисность» нынешнего состояния политологии, как его фиксируют в научной литературе.

Недавно Президент РАПН О. В. Гаман-Голутвина в своей программной статье подчеркивала, что тревожной тенденцией последних лет стала характеристика нынешнего периода эволюции политической науки как кризисного, хотя и не критического [1, с. 20]. В пользу этого утверждения говорит отсутствие на протяжении нескольких десятилетий значимых инновационных идей и эвристически эффективных теорий; широко распространенное искажение методологического инструментария, а также (по В. Патцельту) западный этноцентризм, погруженность в поток настоящего в ущерб историческому контекстуализму, неспособность к критической саморефлексии и непродуктивные отношения с практической политикой.

Все это, к сожалению, так. При этом ряд отечественных и зарубежных авторов дополняет сказанное формулированием некоторых других немаловажных «проблем». Так, Дэвид Лейк, профессор университета Калифорнии, усматривает одну из важнейших аномалий современной политической науки в ее расколах на жестко зафиксированные и догматизированные «-измы», в то время как быстро меняющаяся реальность требует открытого взгляда на происходящее. Он назвал пять основных патологий нашей области знания [2]:

1. Материализация исследовательских традиций - происходит систематическое упрощение выводов для того, чтобы включить их в легко узнаваемые «школы». Иначе говоря, с наилучшими намерениями мы создаем искусственные традиции, которые ошибочно принимаем за состояние дисциплины.

2. Благодаря материализации исследовательских традиций по существу возникает поощрение акцента на крайностях. Это происходит благодаря цитированию одних и тех же канонических источников, что, в конечном счете, ведет вместо формирования общего фундамента для исследований разных направлений к углублению фрагментации дисциплины. Конечно, в определенной степени это организует исследовательский и особенно учебный процесс, однако в сочетании с тремя последующими патологиями скорее препятствует, нежели способствует научной работе. 
3. Исследовательские традиции (парадигмы) смешиваются с конкретными теориями, которые сосуществуют друг с другом, будучи объединенными под «зонтиком» какой-то одной парадигмы. Поскольку исследовательские традиции обычно имеют незавершенный характер, то ученые, как правило, используют исследовательский потенциал теорий, сталкивая их между собой как конкурентов, тем самым демонстрируя принцип «я прав, потому что мой оппонент неправ», но не более того.

4. Мы сужаем предмет нашего исследования, сводя его к тем темам, периодам и наблюдениям, которые имеют тенденцию к подтверждению силы нашей парадигмы. Следствием этого становится сужение исследовательского поля не столько сознательное действие, сколько естественный побочный продукт исследовательского процесса, заставляющий ученого концентрировать внимание именно на тех фактах, которые отвечают его мировоззрению. Благодаря искусственному «зауживанию» парадигмы, она вроде бы вновь и вновь доказывает свою адекватность. Именно в этот момент исследовательские традиции начинают превращаться в теологию (ая бы добавила: во многих случаях в идеологию TAA).

5. Ученые, работающие в рамках каждой из исследовательских традиций, обычно утверждают, что именно их подход является по-настоящему научным. Вместо того чтобы признать, что всякая парадигма ограничена по охвату, мы продолжаем претендовать на интеллектуальную гегемонию, полагая, что именно наша парадигма носит универсальный характер.

Можно привести немало и других критических оценок и замечаний в отношении нынешнего состояния познания политического. Некоторые из них более достоверны, другие - скорее придирчивы, но как бы там ни было, они высвечивают исключительно важную проблему: не просто текущего состояния, но весьма распространенного отсутствия даже упоминания сущностного основания политологического знания и его адекватности задачам, которые ставит перед ним подвижная и неуправляемая действительность.

Понять, какими могут быть «ответы» политологов» на многие современные «вызовы», как представляется, возможно, только обратившись к проблемам познания политического как такового, к онтологии и эпистемологии и посмотрев, что же происходит на этом уровне, а стало быть, к проблеме системного единства познания, признания или, наоборот, отрицания общего в развитии естественно-научного и социального знания. Это весьма наглядно проявилось в истории становления и развития политических наук, которые на разных этапах бросались из крайности в крайность, то отождествляя свои методы с естественно-научными (что, как правило, не удавалось), то претендуя на собственную уникальность, а то и универсальность.

Хотелось бы быть правильно понятой: я отнюдь не стремлюсь, подобно многочисленным предшественникам, снова попытаться привязать естественно-научные методы и утверждения к политологии. Речь идет о другом. Известный австралийский мыслитель Колин Уайт подчеркивает, что социальные науки (и политология в их числе) по определению паразитируют на социальной философии, а та, в свою очередь, на философии науки [3, p. 23]. Причем глагол «паразитирует» не несет негативной коннотации, а лишь подчеркивает неразрывную связь между философией науки и политологическим знанием на всех уровнях, начиная 
с политической философии и кончая методами текущей аналитики (как бы ни пытались от этого откреститься позитивисты всех мастей).

Поэтому речь идет прежде всего о релевантности всякой области знания, в том числе и политического, утвердившейся и признанной в данный исторический момент картине мира. Вопрос о существовании научной картины мира и ее месте в структуре научного знания был поставлен как философами (Л. Виттгенштейн, М. Хайдеггер и др.), так и такими крупнейшими учеными-естественниками, такими как Г. Герц, М. Планк, А. Эйнштейн, Н. Бор, Э. Шредингер. Так, немецкий философ Мартин Хайдеггер (1889-1986) в статье «Время картины мира» разъяснил, что, рассуждая о картине мира, мы в первую очередь думаем об изображении [4]. Как изображение-картина, она не является буквальной копией с оригинала, а фиксирует черты, которые считаются наиболее существенными, значимыми. Мир понимается как все сущее в целом, включающее космос, природу, историю и другие характеристики. Скажем по-другому: картина мира - это изображение «сущего», а мировоззрение - отношение субъекта к сущему. Поэтому историческая субъектность начинается с того момента, когда впервые возникает рефлексия картины мира со стороны человека.

Напомню, что всякая картина мира упрощает и схематизирует действительность. До какого-то момента картина мира отождествляется с самим миром, с реальностью. Новые открытия приводят к крушению «старой» картины мира и появлению и постепенному утверждению новой, но и она - лишь следующая, одна из ступеней эволюции человеческого познания. Научные картины мира оказывают определяющее влияние на рассмотрение политических проблем и специфику их анализа в тот или иной временной период, формируя основания теоретического осмысления процессов и явлений.

Фундаментальная теория конкретной науки может превратиться в научную картину мира, только если ее исходные понятия и принципы приобретут общенаучный и мировоззренческий характер. Поэтому, как правило, речь идет о целой серии взаимосвязанных открытий в фундаментальных науках. Общую картину мира вырабатывает наука, лидирующая в естествознании (обычно это - физика). Соответственно, во-первых, физика обретает онтологический авторитет: иначе говоря, именно эта наука выступает авторитетом относительно того, что есть в мире, а ее законы предполагаются истинными по отношению ко всем объектам в пространстве и времени; во-вторых, физике приписывается эпистемологический авторитет: физика выступает стандартом получения объективного знания о мире. Научность какого-либо положения любой науки определяется возможностью перевести его на язык физики. Положения, не поддающиеся такой операции, рассматриваются как лишённые научного смысла [5].

Специальные науки формируют собственные картины мира вслед за физикой. И политология в этом отношении не может стать исключением. Открытия почти всегда сопровождаются радикальной перестройкой методов исследования, а также значительными изменениями в самих нормах и идеалах научности. Смена картин мира, по существу, означает преобразование как философских оснований научных взглядов, так и нормативных структур исследований, т. е. это своего рода глобальные революции в мировоззрении человека, означавшие также смену типов рациональности (таблица 1). 
Основные характеристики онтологии, эпистемологии и методологии научных картин мира [6]

\begin{tabular}{|c|c|c|}
\hline $\begin{array}{l}\text { Ньютоновская, } \\
\text { механистическая } \\
\text { «классическая» } \\
\text { картина мира }\end{array}$ & $\begin{array}{c}\text { Эйнштейновская } \\
\text { («неклассическая») } \\
\text { картина мира }\end{array}$ & $\begin{array}{c}\text { «остнеклассическая» } \\
\text { картина мира } \\
\text { (Илья Пригожин, } \\
\text { Герман Хакен и др.) }\end{array}$ \\
\hline $\begin{array}{l}\text { - жесткие причинно-след- } \\
\text { ственные связи; } \\
\text { - неизменность простран- } \\
\text { ственно-временных разме- } \\
\text { ров; } \\
\text { - всеобщая взаимосвязь всех } \\
\text { явлений в мире; } \\
\text { - линейный характер изме- } \\
\text { нения объектов; } \\
\text { - приоритет необходимости } \\
\text { над случайностью; } \\
\text { - закономерность происхо- } \\
\text { дящего и т. д. }\end{array}$ & $\begin{array}{l}\text { - вероятностный детерми- } \\
\text { низм; } \\
\text { - относительность про- } \\
\text { странства и времени; } \\
\text { - равноправие и взаимодо- } \\
\text { полнительность необходи- } \\
\text { мости и случайности; } \\
\text { - неевклидов взгляд на про- } \\
\text { странство (искривленность } \\
\text { пространства; опытный, } \\
\text { а не априорный характер } \\
\text { определения пространства); } \\
\text { и т.д. }\end{array}$ & $\begin{array}{l}\text { - индетерминизм; } \\
\text { - приоритет случайности } \\
\text { над необходимостью; } \\
\text { - относительность про- } \\
\text { странства и времени; } \\
\text { - эволюционность и нели- } \\
\text { нейность (бифуркации); } \\
\text { - условность закономерно- } \\
\text { стей в природе и обществе; } \\
\text { - коэволюционность изме- } \\
\text { нений; } \\
\text { и т. д. }\end{array}$ \\
\hline
\end{tabular}

С точки зрения методологии эти вопросы приобрели особенно важное значение в настоящее время на фоне новой неклассической и, наконец, постнеклассической картин мира, однако адаптация политических наук к новому типу мышления сталкивается с изрядными трудностями. Сохраняется наработанная привычка думать и анализировать политические процессы в механистическом ключе. При этом наряду с сохранением влияния чисто механистического подхода имели место попытки обращения к отдельным элементам новых картин мира, в частности к квантовой физике, биологии, использования фактора случайности, отказа от причинноследственных моделей и т. п.

Например, объект микромира в квантовой физике ведет себя в одних случаях как частица, а в других - как волна. Ученые не смогли однозначно интерпретировать такой дуализм, поэтому просто приняли его как данное, то есть в качестве аксиомы. Если при описании объекта микромира выбрать его свойство частицы в качестве основного, тогда получится модель атома, которую выстроил известный физик Нильс Бор. Если же в качестве основного свойства выбрать волну, тогда атом будет похож на размытое пятно. Как одна, так и другая модель работают, отражая многообразие нашего мира. По аналогии (хотя и довольно грубой) в политической науке мы можем рассматривать некий объект исследования, например, как политический институт (частицу), одновременно принимая во внимание максимальную совокупность его взаимосвязей и отношений, в том числе учитывая влияние и восприятие субъекта.

Природа мира едина, но постоянно демонстрирует разные обличья. Имеется лишь один единственный, не подлежащий сомнению факт, который объединяет и примиряет все отрасли знания, - многообразие и многогранность форм проявления реальности. Многовариантность нашего мира является его первейшим фундаментальным свойством. 
Однако в большинстве случаев следует говорить не столько о трансляции методов и подходов из естественных наук в политические, сколько о попытках выстраивания «слабых» вариантов теорий, аналогичных естественно-научным, или некоего подобия (например, квантовоподобных теорий), хотя в целом политические науки, равно как и другие социальные науки, все же стремятся развиваться в духе времени, то есть соответствовать преобладающей картине мира.

На самом деле ничего нового в такой постановке задач, по-видимому, нет. Напомню выступление Президента Американской ассоциации политических наук Вильяма Беннета Мунро (1875-1957), профессора Гарвардского университета и Калифорнийского технологического института, который представил еще в 1927 году президентское обращение к участникам Всеамериканского конгресса политологов под весьма характерным названием - «Физика и политика - пересмотрена старая аналогия» [7].

По-видимому, отнюдь не случайно профессор Мунро начал свое выступление с цитаты Уолтера Бэгехота (1826-1877), британского бизнесмена и журналиста, создателя и владельца знаменитого журнала «Экономист» и ряда других изданий. Не меньшую известность в свое время этот викторианский джентльмен получил как эссеист. В его библиографии важное место заняла книга «Физика и политика», изданная еще в 1872 году, в которой он рассмотрел роль естественных наук, назвав их «физикой», и социальных наук, назвав их «политикой», в становлении человеческой цивилизации и в особенности в обеспечении условий стабильности и социального прогресса. Это была первая заметная попытка применить достижения науки (в особенности дарвинизма) к изучению политики, переосмыслить сложные и зачастую трагические отношения между индивидуальным и коллективным, иначе говоря, определить истинный характер человека политического. По мнению Мунро, работа Бэгехота стимулировала начало осмысления влияния физики на политические идеи человечества, в частности на современные представления в отношении государства и правления. Так, по его мнению, теория эволюции в свое время заставила пересмотреть более старые идеи в отношении происхождения государства и правления, плотнее привязав политическую науку к истории. Как следствие, политологи начали рассматривать публичные институты как часть всего порядка вещей, подобно клеткам в живом организме.

Но физика сделала целый ряд «революционных» шагов в конце XIX - начале $\mathrm{XX}$ века. И вновь политологи оказались перед «вызовами» необходимости пересмотреть традиционные подходы политической науки, на основании которых были выстроены теории об отношениях гражданина и государства, обывателя и правительства, агента и структуры, индивида и коллектива.

Естественные науки, - говорил профессор Мунро, - прошли долгий путь со времен Галилея и Ньютона, в то время как многие политологи по-прежнему с удовольствием опираются на абстрактный формализм Локка, Монтескье, Бентама и других политических мыслителей раннего модерна. Они по-прежнему рассуждают об абсолютных правах и обязанностях, старых аксиомах о суверенитете и общей воле, санкциях по законам, значении общественного мнения, массового поведения, равенстве мужчин и женщин, которые подаются как атомы, составляющие людское содружество. Политологи все еще привязаны к обожествлению индивидуального человека, они все еще основывают свои соображения на том, что может быть названо атомарной теорией политики, то есть подхода, когда все граждане об- 
ладают равным весом, объемом и ценностью, являются носителями равных абсолютных неотчуждаемых прав, выполняют равно абсолютные обязанности, им присущи атрибуты абсолютного суверенитета. Под влиянием идей, заимствованных из натуральной философии, мы продолжаем предполагать, - продолжал он свои рассуждения, - что политология становится наукой только в том случае, если она опирается на серию высших и зафиксированных равномерностей. Наше мышление все еще пронизано метафизическими принципами человеческой свободы, которым должна соответствовать вся правительственная практика. Тем самым Мунро поставил под вопрос чуть ли не все базовые концепты либерализма, вошедшие к этому времени в политическую науку фактически в качестве аксиом.

Изрядно эпатировав собравшихся ученых-политологов, Мунро продолжил: до тех пор, пока социальный порядок был относительно простым, отсутствовали бесчисленные сложности, привнесённые в него за последние полвека (то есть начиная с конца XIX столетия - ТАA), эти старые формулы не выходили за пределы приемлемости со стороны рационального разума, подобно тому, как старые концепты естественных наук вполне удовлетворяли ученых с их лабораторными экспериментами. Сейчас же мы вошли в эпоху, когда огромная лаборатория мировой политики проводит эксперименты любого типа в неизмеримой скорости, а мы пытаемся объяснять нашу электронную динамику в духе механики - то есть практикой, которую ученые-естественники отвергли еще поколение назад.

Поэтому политологии пора начать соответствовать новой физике, обратить внимание на субатомарные возможности, - продолжал Мунро. Иными словами, мы должны отказаться от абсолютов, поскольку ничто не может быть более очевидным, чем предположение, что все гражданские права и обязанности, все формы и методы правления связаны друг с другом, а также со временем, местом и обстоятельствами. Они не могут быть выражены нейтральными формулами. Социальная атмосфера, подобно физической вселенной, наполнена невидимыми единицами энергии, движущимися со всевозможной скоростью и проникающими во власть, оседающими то там, то сям и через какое-то время отлетающими, отталкиваясь от человеческих атомов, дальше. Вес индивида зависит от его способности воспринимать и передавать импульсы, то есть от числа и качества идей, которые он ассимилирует и отпускает. Отсюда - разнообразие отношений граждан к правительству.

Соответственно, вместо формул (а этим изрядно грешит именно наша, отечественная политология - ТАA) политическая наука должна стремиться найти концепты, которые выдержат тест на реальное соответствие, и на этой основе она должна начать перестраивать себя через практически интимные наблюдения происходящего в мире политики. Вывод Мунро содержал четкое указание на то, что по аналогии с новой физикой политическая наука также должна перенести часть своего внимания от крупномасштабных наблюдаемых механизмов политики к невидимым и вследствие этого во многом отрицаемым политологами силам, которые на самом деле приводят в действие и контролируют как поведение индивидуальных граждан, так и политику в целом.

Из сказанного Мунро вывел задачи политической науки как самостоятельной научной дисциплины. Наша ближайшая цель, - сделал вывод Мунро, - должна заключаться в том, чтобы освободить политическую науку от старых метафизических и юридических концептов, на которых традиционно она основывалась, все глубже погружаясь в трясину бессмысленной терминологии. Именно к естественным 
наукам мы можем с наибольшей выгодой обратиться в этот час транзита за предложениями по реконструкции наших постулатов и методов. Политическая наука должна заимствовать по аналогии (курсив мой - ТАA) из новой физики стремление избавиться от интеллектуальной неискренности в отношении природы суверенитета, общей воли, естественных прав и свободы индивида, согласия управляемых, правления большинства, самоуправления, правления общественного мнения, государственных прав, laissez-faire (свободного предпринимательства - TAA), сдержек и противовесов, равенства людей и наций и т. д. Соответственно, вместо этих формул политическая наука должна стремиться найти концепты, которые выдержат тест на реальное соответствие, и на этой основе она должна начать перестраивать себя.

Услышали ли политологи призывы Мунро столетней давности? Есть ощущение, во всяком случае, судя по многочисленным зарубежным и отечественным учебникам политологии, что пока еще нет. По-прежнему преобладают чеканные формулы и концепты, предполагающие заучивание их наизусть подобно мантрам. Мы так и преподаем: посмотрите хотя бы билеты к экзаменам: Что такое суверенитет? Политическая партия? Парламентская система? и т. д. и т. п. Хотя без базовых понятий не обойтись, у студента не возникает понимания, что эти понятия не более чем «сущностно оспариваемые концепты» (В. Гэлли), а стало быть, зависят от контекста, исторического времени, политической культуры, наконец, допускают множественную интерпретацию. Между тем мировая практика предлагает сегодня целый ряд совершенно новых моделей преподавания политических наук, которые реально учат политическому мышлению (например, т. н. «гарвардская модель», предполагающая рассмотрение конкретных актуальных кейсов и обращение к концептам лишь как к справочному материалу, а не наоборот). Впрочем, это требует очень высокого уровня эрудиции преподавателя, когда каждое занятие превращается в «открытие» и обсуждение самых сложных и спорных, но всегда остро актуальных проблем.

Справедливости ради заметим, что в 1990-е гг. в научный лексикон политических наук, включая и теорию международных отношений, все же вошли некоторые понятия и концепты из теоретической физики, термодинамики и теории самоорганизации биологических систем. Однако большинство из них так и не смогло стать операциональными понятиями в силу различий естественно-научного и социального подхода. Обычно они выступали в качестве метафор - они использовались для «сравнения» процессов и явлений качественно различной природы и сложности. Но сама попытка была небесполезна и отчасти даже продуктивна, позволяя глубже понимать социальные процессы.

И тем не менее основной поток политологии продолжает во многом двигаться по инерции. Вроде бы, ничего страшного - вспомним принцип соответствия Нильса Бора, который говорил, что устаревшие представления и методы не исчезают вообще, а могут быть применены как частный случай. Но не слишком ли велик этот «частный случай»? Не подменяет ли он политическую науку неким своего рода катехизисом? В наших исследованиях по-прежнему преобладает механистическая гносеология. Динамичные нелинейные процессы рассматриваются преимущественно в линейно-детерминистском ключе. Очевиден перекос в пользу количественных методов, нередко становящихся самоцелью. Происходит заметное вытеснение методологии, равно как и онтологически-эпистемологических вопросов 
на периферию, а также подмена методологии методикой (т. е. процедурами, техниками, методами, зачастую просто перечисляемыми диссертантами после того, как текст диссертации уже завершен).

Приходится сделать вывод о том, что адаптация политических наук к новым научным картинам мира неизбежна, но тем не менее по определению ограничена: при всем единстве знания как такового методы и инструменты социально-политических и естественных наук весьма различны и даже в процессе приспособления претерпевают столь значительные изменения и упрощения, что зачастую сохраняют лишь наименования и имитацию методологии других наук. И все же как минимум придется следовать сходным курсом. В противном случае мы рискуем не просто безнадежно отстать, но и превратиться в идеологический реликт, более уже не соответствующий ни задачам, ни мышлению сегодняшнего дня.

Таков круг вопросов, которые я предложила бы к обсуждению на нашем первом заседании семинара.

\section{Ссылки / References}

1. Гаман-Голутвина О. В. Преодолевая методологические различия: споры о познании в эпоху неопределенности // ПОЛИС. 2019. № 5. С. 19-42.

2. Lake D. A. Why «isms» Are Evil: Theory, Epistemology, and Academic Sects as Impediments to Understanding and Progress // International Studies Quarterly. 2011. № 55. P. 469-471.

3. Wight C. Philosophy of Social Science and International Relations // Handbook of International Relations. Ed. By Walter Carlsnaes, Thomas Risse-Kappen, Thomas Risse, and Beth A Simmons. London: SAGE, 2002.571 p.

4. Хайдеггер М. Время картины мира // Время и бытие: статьи и выступления. М.: Республика. 1993. С. 41-63.

5. Юлина Н. С. Что такое физикализм? Сознание, редукция, наука // Философия науки. Вып. 12: Феномен сознания. М.: Институт философии РАН, 2006. С. 9-42.

6. Алексеева Т. А. Теория международных отношений как политическая философия и наука. М.: Аспект-пресс, 2020. 608 с.

7. Munro W. B. Physics and Politics - an Old Analogy Revised // The American Political Science Review. February 1928. Vol. XXII. № 1. URL:

https://www.cambridge.org/core/content/view (дата обращения: 24.02.2020). 